\title{
ЛИНГВОМЕТОДИЧЕСКИЙ ПОТЕНЦИАЛ ИНФОГРАФИКИ НА ЗАНЯТИЯХ ПО ПРАКТИЧЕСКОМУ КУРСУ РУССКОГО ЯЗЫКА СО СТУДЕНТАМИ АЗИАТСКО-ТИХООКЕАНСКОГО РЕГИОНА
}

\author{
Е. С. Кудлик', А. Б. Антонова², И. Ю. Капичникова' \\ ${ }^{1}$ Байкальский государственный университет, г. Иркутск, Российская Федерация \\ 2 Иркутский государственный университет, г. Иркутск, Российская Федерация
}

\author{
Информация о статье \\ Дата поступления \\ 15 июня 2017 г. \\ Дата принятия к печати \\ 12 июля 2017 г. \\ Дата онлайн-размещения \\ 15 сентября 2017 г.

\section{Ключевые слова \\ Инфограффика; студенты Азиатско-Тихоокеанского региона; русский язык; визуализация данных; средства обучения}

\begin{abstract}
Аннотация
В статье рассматривается лингвометодический потенциал инфографики как средства обучения в рамках реализации базового дидактического принципа наглядности на уроках русского языка как иностранного. В национальном и поколенческом аспектах определяются особенности мышления современных студентов Азиатско-Тихоокеанского региона и восприятия ими иноормации. Описываются принципы создания инфографических материалов для занятий по практическому курсу русского языка. Кроме того, в статье представлен проект инфографики «Стандартный сценарий жизни в разных странах» с упражнениями на различные виды речевой деятельности в рамках уровневого подхода к преподаванию и изучению русского языка как иностранного, утвердившегося в современной методике РКИ. Инфографика, являясь основой для внедрения активных и интерактивных форм обучения, обеспечивает соответствие требованиям к организации учебного процесса в вузе, заявленным в федеральных государственных образовательных стандартах высшего профессионального образования.
\end{abstract}

\section{LINGUO-DIDACTIC POTENTIAL OF INFOGRAPHICS IN RUSSIAN LANGUAGE LESSONS FOR ASIAN-PACIFIC STUDENTS}

\author{
Elizaveta S. Kudlik', Alla B. Antonova², Inna Yu. Kapitchnikova' \\ ${ }^{1}$ Baikal State University, Irkutsk, Russian Federation \\ ${ }^{2}$ Irkutsk State University, Irkutsk, Russian Federation
}

\author{
Article info \\ Received \\ June 15, 2017 \\ Accepted \\ July 12, 2017 \\ Available online \\ September 15, 2017

\section{Keywords \\ Infographics; Asian-Pacific students; Russian language; data visualization; teaching tools}

Нарастание объемов инорормации и стремительное развитие информационно-коммуникационных технологий, характерное для цифровой эпохи, требуют переосмысления базовых принципов обучения. С одной стороны, развитие технологий приводит к появлению нового инструментария, который может быть использован в преподавании иностранных язы-

\begin{abstract}
The article deals with the linguo-didactic potential of infographics as a tool for teaching Russian as a foreign language, founded on the basic didactic principle of data visualization. The peculiarities of modern Asian-Pacific students' ways of thinking and information perception are defined in terms of national and generational aspects. The principles of creating infographic texts for Russian as a foreign language lessons are described. The authors also present the infographic project «A typical life scenario in different countries"; this project includes tasks to instill various RFL skills and adopts methods widely accepted in the field. Rooted in the implementation of active and interactive teaching methods, infographics adeptly fulfills the requirements for high school organization stated in the Federal State Educational Standards of Higher Professional Education.
\end{abstract}

ков. С другой стороны, цифровая революция создала совершенно новый тип студентов, названных американским писателем Марком Пренски «цифровыми жителями», с рождения находящимися под воздействием цифровых технологий в отличие от предшествующего поколения - «цифровых гостей», сфрормировавшихся в доцифровую эпоху [1, с. 1]. 
У поколения «цифрровых жителей» преобладает новый тип мышления, определяющийся исследователями через понятия нелинейного, клипового и визуального мышления.

Под нелинейным мышлением понимается тип мышления, при котором реализуется стратегия ориентации в сложноорганизованной и быстроменяющейся системе современного мира, а также способ восприятия и интерпретации этой сложности [2, с. 30]. «Развитие электронных средств коммуникации возвращает человеческое мышление к дотекстовой эпохе, и линейная последовательность знаков перестает быть базой культуры» [3, с. 86].

В результате развития информационно-коммуникационных технологий формируется особенность восприятия мира через короткие яркие образы и послания, называемая клиповым мышлением. Клиповое мышление, с одной стороны, не позволяет своему носителю сконцентрироваться и углубиться в изучаемый вопрос, однако, с другой стороны, способствует развитию многозадачности и защищает мозг от информационной перегрузки.

Под визуальным мышлением понимается мышление посредством визуальных операций, когда визуальные образы не просто иллюстративны, а являются инструментом моделирования мира [2, с. 30].

В связи с тем что в основе описанных выше типов мышления лежит визуальное восприятие, необходимо иначе взглянуть на принцип наглядности на уроках РКИ.

Принцип наглядности является самым древним и наиболее интуитивно понятным. Визуальные образы применяются как средство обучения и средство познания [4, с. 29]. $\mathrm{Ha}$ занятиях РКИ наглядность позволяет мобилизовать психическую активность студентов, вводить новый материал, повышать мотивацию, систематизировать знания, выделять главное и второстепенное, снижать утомление, увеличивать возможность непроизвольного запоминания и др. На уроках иностранного языка под реализацией принципа наглядности традиционно в узком смысле понимается использование визуальных и аудитивных средств, в широком - создание условий, в которых могла бы функционировать речь, передающая информацию в коммуникативных целях [5, с. 60].

Опора на зрительный образ особенно актуальна в случае обучения студентов Азиатско-Тихоокеанского региона (далее ATP), поскольку когнитивные характеристики личности таких обучающихся включают конкретно-метафорический стиль мышления и «визуальность» как желательный способ получения инорормации. На практике это проявляется в том, что студенты предпочитают зрительные невербальные образы в виде таблиц, рисунков и схем, поэтому студентам АТР при предъявлении нового материала недостаточно только его устной презентации [6]. И. Е. Бобрышева, сравнивая учебный процесс в странах Европы и Дальнего Востока, также называет зрительную модальность на основе моторики (опора на текст, письменная фиксация) и образное ассоциирование среди особенностей организации учебно-познавательной деятельности в последних [7, с. 39].

Как пишет Л. Р. Коул, в обучении языку должна использоваться более разнообразная техника с большей изобретательностью изображений, чем это имеет место в современных аудиовизуальных курсах [8, р. 349].

На наш взгляд, эту «более разнообразную технику» для обучения РКИ сегодня демонстрирует инфографика.

Инфографика в широком смысле слова (от лат. informatio «осведомление, разъяснение, изложение» и др.-греч. үрафıко́ «пись-

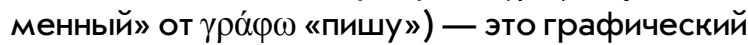
способ подачи информации, данных и знаний'.

Применительно к обучению языкам инфрографику определяют как средство наглядности, средство обучения, способ обучения, принцип обучения и т. д. А. Е. Басырова отмечает, что инфогграфика - это тот вид представления информации, который способен одновременно быть и средством, и способом обучения. Под данным термином исследователь понимает «способ представления информации, сведений или знаний с помощью комбинации вербального и иллюстративного компонентов, предназначенный для быстрой и лаконичной презентации темы, а также призванный улучшить восприятие информации и мотивировать к прочтению». А. Е. Басырова вводит термин «инорографический текст» и считает инфографиику разновидностью креолизованных текстов [9, с. 24].

В рамках данной статьи мы определяем инфрографику как одно из средств обучения языку, реализующее принцип наглядности и позволяющее информативно, понятно и интересно визуализировать при помощи текстов, цифр, картинок и геометрических фигур большой объем информации, данных и знаний. Основными характеристиками инфографрики мы считаем следующие: информативность, компактность, краткость,

'URL: http://dic.academic.ru/dic.nsf/ruwiki/1378426. 
большие визуальные возможности и широкий лингвометодический потенциал.

В аудитории инфографика может служить следующим целям:

- так называемый мозговой штурм (brain storming);

- обмен данными (sharing data);

- сопоставление, поиск аналогий (making comparisons);

- объяснение понятий или презентация процессов (explaining concept or presenting process);

- обеспечение дополнительной информацией помимо учебников (providing more information other than textbook) и т. д.

Инфографика в первую очередь ассоциируется с наглядным способом презентации данных, она легка в понимании, поскольку состоит из образов, графиков, таблиц, рисунков и т. д. Инфографика позволяет легко вовлечь студента в процесс обучения и создать на занятии дружескую атмосферу. Результатами инорографики можно поделиться в Интернете, что, несомненно, актуально в наше время, когда соцсети являются неотъемлемой частью жизни. Преподаватель создает инфографики по теме своего занятия, а затем постит их в соцсетях. Студенты делятся заинтересовавшими их инфографиками со своими друзьями, что создает эфффект так называемого снежного кома (a snowball effect) ${ }^{2}$.

С одной стороны, «обслуживая» такое большое количество задач, инфографика должна быть очень информативна, с другой стороны, «инфографика не должна подразумевать квест» [10]. Кроме того, преподавателю необходимо так представить информацию на инфрографике, чтобы она не только читалась быстро и понятно, но и воспринималась недвусмысленно. Л. Л. Вохмина выделяет набор принципов, которые позволяют повысить «читабельность» визуальной наглядности и которые, на наш взгляд, должны реализовываться в случае использования инфографики на занятиях по РКИ: 1) отбор и выделение существенных черт (не должно быть перегрузки излишними деталями и предметами, вызывающими посторонние ассоциации и комментарии учащихся на родном языке); 2) причинность (события должны быть объединены причинной связью, поскольку изолированный факт может ассоциироваться с самыми различными ситуациями); 3) временна́я последовательность (объединение событий на основе следования

${ }^{2} 4$ Reasons to Use Infographics in the Classroom. URL: https: / / www.edrawsoft.com/infographics/why-useinfographics-in-classroom.php. по времени); 4) генерализация (для того чтобы идея, объединяющая сходные события, была ясной, целесообразно использовать несколько рисунков); 5) противопоставление (сравнение двух предметов или явлений по контрасту); 6) учет психологических особенностей восприятия (знание закономерностей между порядком расположения предметов на картинке и их восприятием); 7) опора на изученный языковый материал [5, с. 62-63].

Что касается технической стороны вопроса, то в качестве инструмента для создания качественной инфрографрики можно использовать один из графических редакторов либо специально предназначенный для этого сайт.

Для работы на уроке РКИ можно привлекать как уже готовую инфографику, разработанную специалистами по дизайну и размещенную на специализированных pecypcax (infographicsmag, Style and Flow, Good.is, InfographicGallery, Visual.ly, Cool Infographics), так и самостоятельно созданные инфографические материалы.

На продвинутом этапе обучения, когда у студентов сорормирована базовая коммуникативная компетенция, представляется возможным использовать аутентичные инфографические тексты по разным областям знаний, дополняя ими традиционные текстовые материалы. Необходимо внимательно подходить к выбору инфографики для работы на уроке, учитывая тематику и принимая во внимание то обстоятельство, что не все художественные усовершенствования, предложенные дизайнером-разработчиком для своей целевой аудитории, найдут адекватный отклик у иностранных студентов.

В этой связи мы решили предложить собственный проект инфографики, а также разработать упражнения, иллюстрирующие лингвометодический потенциал инфографики в качестве нового средства обучения русскому языку как иностранному студентов АТP.

Была выбрана тема "Стандартный сценарий жизни в разных странах», так как, на наш взгляд, она проявляет свою универсальность для студентов разных уровней и может быть рассмотрена в ракурсе тем, актуальных для говорящего как личности, а также относящихся к сорере межкультурной коммуникации. Кроме того, данная тема соотносится с темами первого уровня (ТРКИ-1) («Биография», «Система образования», «Образ жизни») [11, с. 8] и второго уровня (ТРКИ-2) («Человек и его личная жизнь», «Семья», «Работа», «Мужчина и женщина», «Дети и родители») [12, с. 10].

Таким образом, был предложен стандартный сценарий жизни на основе материа- 
лов статистики относительно возраста начала обучения, создания семьи, деторождения, выхода на пенсию и средней продолжительности жизни для мужчин и женщин из России, США, Японии, Южной Кореи и Китая.

C помощью сервиса Canva была создана инфографика, демонстрирующая эту информацию. Сервис Canva имеет интуитивно понятный интерфейс, содержит готовые шаблоны, элементы, иллюстрации для создания инфографики, а также позволяет добавлять собственные фотографии. Также сервис предоставляет возможность скачивания готового материала в формате PDF, JPEG, PNG и размещения его в социальных сетях.

При составлении инфографики мы использовали принципы, описанные выше, которые можно применить к любой визуальной наглядности, а также принципы, предложенные американским инфографом Джошуа Джонсоном, специфичные для подачи материала с помощью данной технологии.

Во-первых, необходимо, чтобы смысл отдельных фрагментов инфографики и общей идеи воспринимался мгновенно, за считанные секунды. Для этого информация должна быть обращена в графическую метафрору, понятную представителям разных культур. В этой связи была использована шкала времени в виде каната синего цвета - для мужчин и розового - для женщин, а также желтые круги с цифрами, указывающими на возраст, на который приходится то или иное жизненное событие.

Во-вторых, одним из ключевых элементов дизайна при создании инфографики является повтор. Этот инструмент особенно уместен в инфографике, демонстрирующей одни и те же данные в различных контекстах, в нашем случае контекстом является страна, а повтором - графическая метафора жизни и знаковых остановок.

В-третьих, инфографика должна рассказывать историю, основываться на визуальном ряде и не слишком полагаться на текст. Конечно, текст может присутствовать, однако иллюстративный материал и сам по себе должен очень хорошо передавать смысл [13]. Из текстовых элементов мы оставили только название страны, а остальную информацию передали иллюстрациями.

На наш взгляд, чем меньше текстовых элементов и чем точнее подобраны графические метафоры и иллюстрации, тем больший методический потенциал для уроков РКИ имеет инфографика. Для каждой страны с помощью ее представителей были подобраны свои иллюстрации, отражающие те или иные ее культурные реалии, а принцип повтора, о котором мы говорили выше, позволяет студенту правильно интерпретировать незнакомые культурные коды после сопоставления с тем фррагментом, в котором речь идет о родной для него культуре.

Мы предлагаем следующие типы заданий по инфографике «Стандартный сценарий жизни в разных странах " на занятиях по практическому курсу русского языка со студентами АТР уровня В1.

На подготовительном этапе работы учащимся можно задать вопросы о том, когда они пошли в школу, когда поступили в университет, кем они хотят стать в будущем, как они представляют свою жизнь через 5, 10, 20, 30 лет. После предлагается ввести лексему «сценарий», объяснив прямое значение (сценарий фильма) и переносное (сценарий жизни).

На следующем этапе студентам презентуется инфографика и задаются вопросы, которые позволяют учащимся ее прочитать и интерпретировать увиденную информацию: «Как вы думаете, что изображено на этих графиках? О какой стране идет речь? Что означают цифры? Какие события жизни человека вы можете назвать? Это важные события в жизни человека? Почему? Почему здесь изображены линии голубого и розового цветов? Речь идет о конкретном мужчине или женщине? Илио среднестатистическом, обычном?» (рис. 1). На этом этапе возможно активизировать лексику, изученную студентами в рамках темы «Биография», а также объяснить новые лексические единицы, используя инфографику, например: среднестатистический россиянин, свадьба, первый ребенок, пенсия, пожилое поколение; идти пойти в первый класс, выходить - выйти замуж (за кого?), жениться (на ком?), стать родителями, выходить - выйти на пенсию, умирать - умереть.

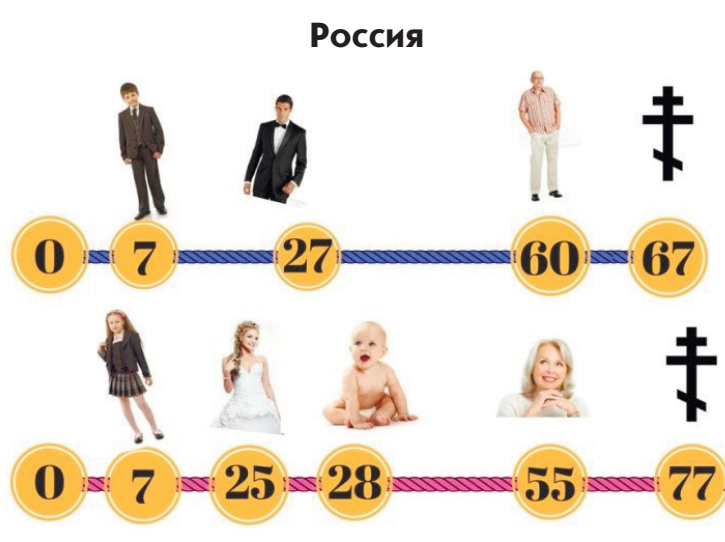

Рис. 1 
Отметим, что с помощью инфографики можно расширять словарный запас студентов, работая над синонимическими рядами и объясняя стилистическую разницу: идти - пойти в школу, начинать - начать обучение в школе; свадьба - брак, выходить - выйти замуж, жениться, заключать брак, создать семью; стать родителями, заводить ребенка/детей, родить ребенка; выходить - выйти на пенсию, уходить - уйти на пенсию, уходить уйти на заслуженный отдых, завершить трудовую деятельность; умирать - умереть, уходить - уйти в мир иной; первый ребенок - первенец; жена - супруга, муж - супруг.

Закрепить использование того или иного стилистического варианта помогают следующие типы заданий, например для китайских студентов: “Создайте график со стандартным сценарием жизни для представителя своей страны. Расскажите о сценарии жизни среднестатистического китайца» (рис. 2).

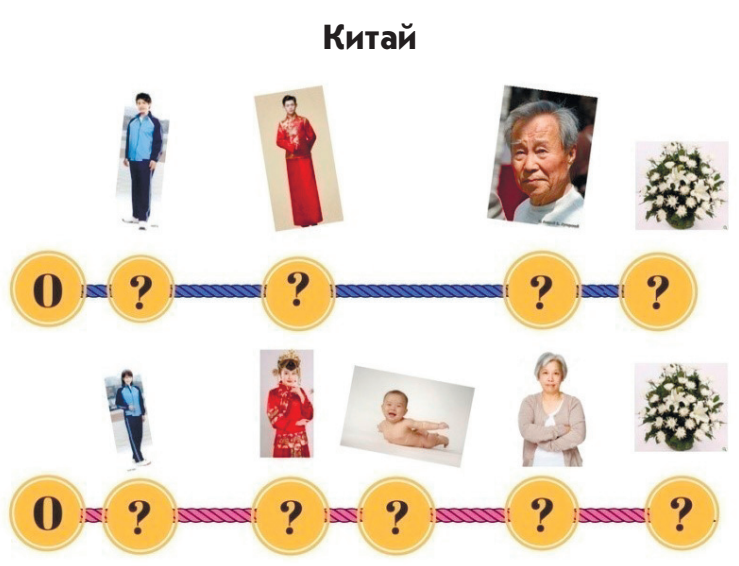

Рис. 2

Кроме того, инфографика может служить базой для обсуждения проблемных вопросов, например: «Расскажите, как живут типичные школьники в вашей стране? Как живут молодые люди? С какими проблемами сталкивается молодая семья? Во сколько лет человек выходит на пенсию в вашей стране? Обсуждают ли в вашей стране вопрос повышения пенсионного возраста?».

Инфрографика может быть также использована в качестве варианта сценария ролевой игры.

Вариант 1 (индивидуальная работа). «Вас зовут Ким Хансу. Вы кореец. Вам 70 лет. Расскажите о своей жизни» (рис. 3).

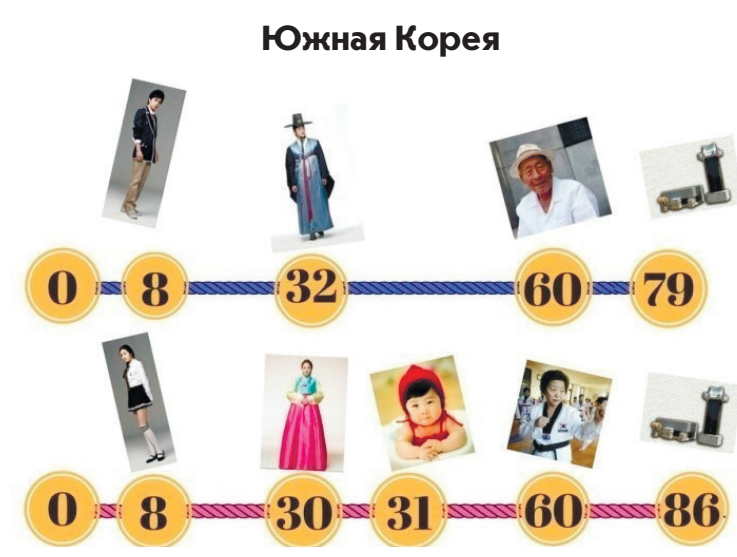

Pис. 3

Вариант 2 (работа в парах). «Вы пожилая семейная пара из Америки. Вас зовут Джон и Сара Джонс. Вам 70 и 68 лет соответственно. Вы прожили долгую и счастливую жизнь. Придумайте историю жизни своим героям» (рис. 4).

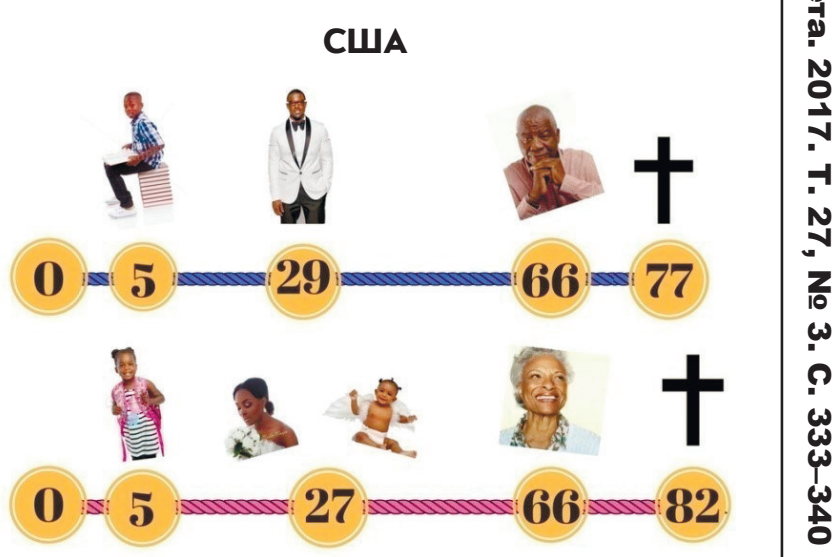

Pис. 4

Можно предложить студентам список вопросов, которые возможно использовать при подготовке этого задания: «Где и когда вы родились? В каком возрасте вы пошли в школу? Когда вы поступили в университет? Какие предметы вы изучали? Кем вы работали? Когда вы встретили свою любовь? Расскажите историю своей любви. В каком возрасте вы создали семью? В каком возрасте у вас появился первый ребенок? Сколько у вас детей? У вас есть внуки? В каком возрасте вы пошли на пенсию? Кто раньше из вас пошел на пенсию? Чем вы занимаетесь на пенсии?»

Также можно усложнить сценарий игры, попросив студента изменить в своем рассказе среднестатистические показатели, увеличив их на несколько лет, а группу - догадаться, о какой стране идет речь, аргументировав 
свою позицию. Например: «Я пошла в школу, когда мне было 8 лет. В возрасте 31 года я вышла замуж, а через год стала мамой. Сейчас мне 74, а два года назад я закончила трудовую деятельность».

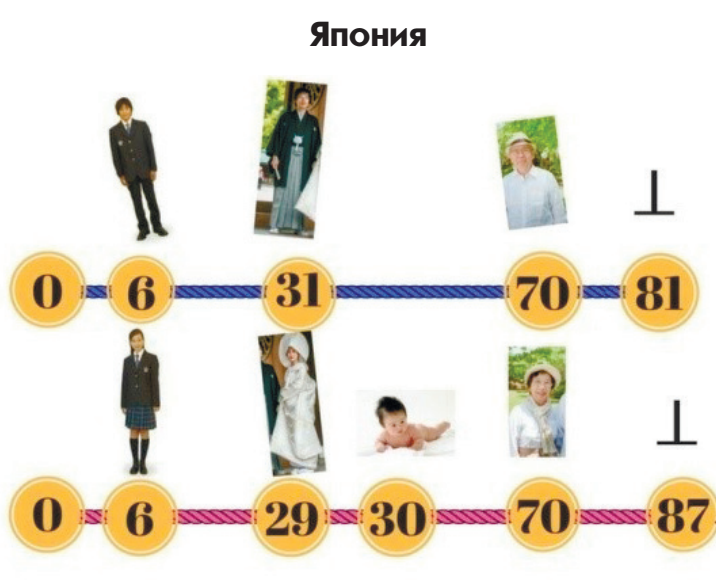

Puc. 5

Другой вариант усложнения - игра «Разрыв шаблона - я белая ворона»: «B изученной нами инфографике вы увидели сценарий жизни среднестатистического человека. Представьте, что вы - очень необычный человек, всю свою жизнь вы - белая ворона и живете не так, как все. Расскажите свою историю, придумайте причины, которые привели к тому, что ваша жизнь не похожа на жизнь среднестатистического представителя вашей страны». Речевые модели: «Обычно дети в моей стране идут в школу, когда им исполняется 7 лет, а я пошел в школу, когда мне было 6 лет, потому что... Обычно молодые люди в моей стране женятся/ выходят замуж/вступают в брак в возрасте..., а я..., потому что... Обычно люди в моей стране становятся родителями в... лет, а я..., потому что... Обычно люди в моей стране выходят на пенсию в... лет, а я..., потому что...»

Данная инфографика может служить основой для заданий на развитие письменной речи: «Напишите автобиографию человека; напишите статью о жизни среднестатистического россиянина; составьте аналитическую справку, в которой аргументируйте необходимость повышения/ понижения пенсионного возраста; напишите эссе на тему «Я через 40 лет», "Сценарий жизни», "Планы на будущее».

Кроме того, возможно возвращение студентов к данной инфографике с усложнением типов заданий и привлечением активных методов обучения на продвинутом этапе обучения. Например, проведение дебатов на темы «Повышение пенсионного возраста», «Права женщин», «Идеология чайлдфри», «Почему мужчины умирают раньше?» - для развития устной речи, составление аналитической справки, аргументирующей необходимость повышения/понижения пенсионного возраста, - для развития письменной речи.

В рамках данной статьи мы показали, как один и тот же инфографический проект может использоваться на практических занятиях по русскому языку. Отметим, что приведенный инфографический текст может быть применен и на других аспектах и дисциплинах при обучении студентов АТP русскому языку. Так, на занятиях по практике перевода предложения с тренируемыми лексическими, грамматическими и стилистическими конструкциями можно привести на родном языке учащихся, а затем предложить сделать перевод этих предложений на русский язык.

На тренировку «математического» русского языка могут быть направлены вопросы типа: «На сколько лет меньше живет мужчина, чем женщина, в России/Китае/ Японии/Корее/Америке? На сколько процентов средняя продолжительность жизни мужчины/женщины в Америке ниже, чем в Японии».

На практикуме по межкультурной коммуникации студентам могут быть предложены следующие упражнения: «При помощи статистических данных, представленных на инфографике, докажите эти утверждения/подискутируйте на тему этих утверждений, являющихся верными для Кореи: "За последние 40 лет Корея сделала громадный шаг из средневековья в современность в области прав женщин", "Социологи предсказывают, что если необходимые меры не будут приняты, то в 2020 г. начнется сокращение населения страны"». И так далее.

При затруднениях преподаватель может направить студентов на конкретную информацию на инфографике (возраст рождения первенца, ограниченность репродуктивного периода женщин и т. д.). Заметим, инфографрика является эфффективной даже в том случае, если необходимо представить информацию по теме, которая по каким-либо (например, религиозным и т. д.) соображениям является табу для обсуждения в культурной среде студента. С такой ситуацией можно часто столкнуться преподавателю, работающему в мультинациональной аудитории.

Продолжением этого упражнения может стать следующее: “Докажите, что эти 
утверждения верны/неверны для вашей страны». В качестве вариации задания можно предложить порассуждать на темы: «Как вы думаете, для какой страны могут быть/ не могут быть верны эти утверждения?», «Назовите приметы социального прогресса страны». В этом случае студенты должны проанализировать продолжительность жизни и «выйти на разговор» о возможных причинах (развитие здравоохранения, улучшение качества питания, деятельность салонов красоты ит. д.).

«Выделите те показатели, которые могут быть обусловлены социальными/ религиозными/экономическими обстоятельствами. На какую из статистических норм могут влиять исторически сложившиеся традиции страны?»

Отметим, что все эти задания могут быть повторены на занятиях по тем же самым дисциплинам, но в рамках второго иностранного языка (например, английского).

Итак, на небольшом проекте инфографики мы продемонстрировали, насколько безграничным является ее потенциал в лингвистическом и методическом планах. Сфрормулируем основные выводы относительно использования инфрографики при обучении студентов АТР практическому курсу русского языка.

При использовании инфографики на занятиях необходимо учитывать национальную принадлежность студента, тип его личности, ведущий способ получения информации и т. д.

Данное средство обучения обладает широкими визуальными и информативными возможностями. Инфографические тексты кратки и компактны, при этом прекрасно реализуют принцип наглядности и позволяют доступно и интересно презентовать большой объем информации, что является основным преимуществом при обучении студентов ATP, у которых когнитивный стиль познавательной деятельности подразумевает опору на зрительный образ.

Задания с использованием инфографики могут быть направлены на развитие всех видов речевой деятельности и вовлечены во все виды работ на занятии: фрронтальная, групповая и индивидуальная.

Инфографика позволяет преподавателю учить студента в режиме «нон-стоп». Обсудив материал на занятии, наставник может создавать информативные инфографики и делиться ими со студентами в соцсетях в любое время помимо аудиторных часов. Инфографика дает возможность экономить время педагога и расходовать его с большей эфрфективностью, поскольку один и тот же инфографический текст может использоваться при обучении студентов с разным уровнем владения русским языком.

Отметим также, что инфографика - это уникальная возможность обеспечения междисциплинарных связей. Ни одно средство обучения не будет так "бить в одну точку», как инфографика. Один и тот же инфографический текст может с легкостью «подстраиваться» под различные дисциплины, при этом студенты будут эффрективно, быстро и с интересом осваивать нужные лексические единицы, грамматические и стилистические конструкции на разных занятиях, что является несомненным плюсом в графике работы преподавателя с большой аудиторной нагрузкой и разрозненностью курсов, дисциплин и профрильных направленностей.

\section{СПИСОК ИСПОЛЬЗОВАННОЙ ЛИТЕРАТУРЫ}

1. Prensky M. Digital natives, Digital immigrants / M. Prensky // On the Horizon. — 2001. — Vol. 9, № 5. P. 1-6.

2. Тенхунен П. Ю. Особенности восприятия учебной информации современными студентами: потенциал визуальной концептуализации / П. Ю. Тенхунен, Ю. А. Елисеева / / Интеграция образования. - 2015. T. 19, № 4. - C. 28-33.

3. Маклюэн М. Галактика Гуттенберга: Становление человека печатающего / М. Маклюэн. - М. : Акад. проект, 2005. - 496 с.

4. Щукин А. Н. Методика преподавания русского языка как иностранного для зарубежных филологов-русистов / А. Н. Щукин. - М. : Рус. яз., 1990. - 231с.

5. Вохмина Л. Л. Некоторые проблемы использования наглядности в обучении иностранным языкам / л. Л. Вохмина / / Русский язык за рубежом. - 1978. - № 5. - С. 60-64.

6. Попова Е. В. Языковая личность корейского студента-филолога в лингводидактическом аспекте / Е. В. Попова / / Гуманизация образования. - 2008. - № 5. - С. 53-58.

7. Бобрышева И. Е. Модель коррекции заданий и упражнений с учетом культурно-типологических стилей учебно-познавательной деятельности / И. Е. Бобрышева / / Русский язык за рубежом. - 2004. - № 1. С. $38-48$.

8. Cole L. R. Relationships between visual presentations and linguistic items in second language teaching / L. R. Cole / / International Review of Applied Linguistics in Language Teaching. - 1976. - Vol. 14. - P. 339-350.

9. Басырова А. Е. Инфографический текст как новое средство наглядности на уроках РКИ / А. Е. Басырова // Материалы 4-й Международной научно-методической конференции. - Воронеж : Науч. кн., 2016. - C. 22-26. 
10. Симаков М. Инфографика: как это работает [Электронный ресурс] / М. Симаков. - Режим доступа: https: / /test.ru/reports/infograph-meetup.

11. Требования по русскому языку как иностранному. Первый уровень. Общее владение. Второй вариант / Н. П. Андрюшина [и др.]. - М. : СПб. : Златоуст, 2009. - 32 с.

12. Государственный образовательный стандарт по русскому языку как иностранному. Второй уровень. Общее владение / Т. А. Иванова [и др.]. - М. ; СПб. : Златоуст, 1999. - 40 с.

13. Johnson J. 10 Tips for Desining Better Infographics [Electronic resource] / J. Johnson. - Mode of access: https://designshack.net/articles/graphics / 10-tips-for-designing-better-infographics.

\section{REFERENCES}

1. Prensky M. Digital Natives, Digital Immigrants. On the Horizon, 2001, vol. 9, no. 5, pp. 1-6.

2. Tenhunen P. Yu., Eliseeva Yu. A. The Peculiarities of Educational Information Perception by Modern Students: the Potential of Visual Conceptualization. Integraciya obrazovaniya = Integration of Education, 2015, vol. 19, no. 4, pp. 28-33. (In Russian).

3. McLuhan M. The Gutenberg Galaxy: The Making of Typographic Man. Toronto, University of Toronto Press, 1962. 293 p. (Russ. ed.: McLuhan M. Galaktika Guttenberga: Stanovlenie cheloveka pechatayushchego. Moscow, Akademicheskii proekt Publ., 2005. 496 p.).

4. Shchukin A. N. Metodika prepodavaniya russkogo yazyka kak inostrannogo dlya zarubezhnyh filologovrusistov [The Method of Teaching Russian as a Foreign Language for Foreign Philologists-Specialists in Russian Philology]. Moscow, Russkii yazyk Publ., 1990. 231 p.

5. Vohmina L. L. Some Problems of Using Visual Presentations in Teaching Foreign Languages. Russkij yazyk za rubezhom = Russian Abroad, 1978, no. 5, pp. 60-64. (In Russian).

6. Popova E. V. Linguistic Persona of a Korean Student-Philologist in Linguo-Didactic Aspect. Gumanizaciya obrazovaniya $=$ Humanization of Education, 2008, no. 5, pp. 53-58. (In Russian).

7. Bobrysheva I. E. The Model of Tasks and Exercises Correction with Regard to the Cultural-Typological Styles of Learning and Cognitive Activity. Russkij yazyk za rubezhom = Russian Abroad, 2004, no. 1, pp. 38-48. (In Russian).

8. Cole L. R. Relationships between Visual Presentations and Linguistic Items in Second Language Teaching. International Review of Applied Linguistics in Language Teaching, 1976, vol. 14, pp. 339-350.

9. Basyrova A. E. Infographic Text as a New Data Visualization Teaching Tool in Russian as a Foreign Language Lessons. Materialy 4-i Mezhdunarodnoi nauchno-metodicheskoi konferentsii [Materials of $4^{\text {th }}$ International Scientific and Methodological Conference]. Voronezh, Nauchnaya kniga Publ., 2016, pp. 22-26. (In Russian).

10. Simakov M. Infografika: kak ehto rabotaet [Infographics: How it Works]. Available at: https://test.ru/ reports/infograph-meetup. (In Russian).

11. Andryushina N. P. et al. Trebovaniya po russkomu yazyku kak inostrannomu. Pervyi uroven'. Obshchee vladenie. Vtoroi variant [Standard of Competence in Russian as a Foreign Language. B1. Threshold or Intermediate]. Moscow, Saint Petersburg, Zlatoust Publ., 2009. 32 p.

12. Ivanova T. A. et al. Gosudarstvennyi obrazovatel'nyi standart po russkomu yazyku kak inostrannomu. Vtoroi uroven'. Obshchee vladenie [State Standard of Competence in Russian as a Foreign Language. B2. Vantage or Upper Intermediate]. Moscow, Saint Petersburg, Zlatoust Publ., 1999. 40 p.

13. Johnson J. 10 Tips for Designing Better Infographics. Available at: https://designshack.net/articles/ graphics/10-tips-for-designing-better-infographics.

\section{Информация об авторах}

Кудлик Елизавета Сергеевна - старший преподаватель, кафедра языковой подготовки, Байкальский государственный университет, 664003, г. Иркутск, ул. Ленина, 11, e-mail: liseron@mail.ru.

Антонова Алла Борисовна - кандидат филологических наук, доцент, кафедра русского языка как иностранного, Иркутский государственный университет, 664025, г. Иркутск, ул. Ленина, 8, e-mail: allabb@yandex.ru.

Капичникова Инна Юрьевна - кандидат филологических наук, доцент, директор Института иностранных языков, заведующий кафедрой журналистики, Байкальский государственный университет, 664003, г.Иркутск, ул. Ленина, 11, e-mail: innakap@yandex.ru.

\section{Для цитирования}

Кудлик Е. С. Лингвометодический потенциал инфограсрики на занятиях по практическому курсу русского языка со студентами Азиатско-Тихоокеанского региона / Е. С. Кудлик, А. Б. Антонова, И. Ю. Капичникова // Известия Байкальского государственного университета. - 2017. - Т. 27, № 3. - С. 333-340. DOI : 10.17150/2500-2759.2017.27(3).333-340.

\section{Authors}

Elizaveta S. Kudlik - Senior Lecturer, the Department of Language Training, Russian-Chinese Faculty, Baikal State University, 11 Lenin St., 664003, Irkutsk, Russian Federation, e-mail: liseron@mail.ru.

Alla B. Antonova - PhD in Philology, Associate Professor, the Department of Russian as a Foreign Language, Irkutsk State University, 8 Lenin St., 664025, Irkutsk, Russian Federation, e-mail: allabb@yandex.ru.

Inna Yu. Kapitchnikova - PhD in Philology, Associate Professor, Director of the Institute of Foreign Languages, Head of the Department of Journalism, Baikal State University, 11 Lenin St., 664003, Irkutsk, Russian Federation, e-mail: innakap@yandex.ru.

\section{For Citation}

Kudlik E. S., Antonova A. B., Kapitchnikova I. Yu. Linguo-Didactic Potential of Infographics in Russian Language Lessons for Asian-Pacific Students. Izvestiya Baykal' skogo gosudarstvennogo universiteta $=$ Bulletin of Baikal State University, 2017, vol. 27, no. 3, pp. 333340. DOI: $10.17150 / 2500-2759.2017 .27(3) .333-340$ (In Russian). 